\title{
DA CONSTITUIÇÃO FEDERAL DE 1988 \\ AO PLANO NACIONAL DE EDUCAÇÃO 2014-2024: ardilosas apropriações da noção de valorização do trabalho docente
}

\author{
FROM THE FEDERAL CONSTITUTION OF 1988 \\ TO THE NATIONAL PLAN OF EDUCATION 2014-2024: \\ cunning appropriations of valorization's notion of the teacher's work
}

\author{
Robson da Silva Rodrigues* \\ Áurea de Carvalho Costa ${ }^{* *}$
}

\begin{abstract}
Resumo
O objetivo deste artigo foi apreender as noções de valorização do trabalho do professor presentes nas políticas educacionais federais. Realizamos análises bibliográficas e documentais sobre o referencial teórico do materialismo histórico dialético. A desvalorização verificada no cotidiano escolar e sobre aqueles que concretizam a prática educativa contradiz as políticas educacionais que diziam almejar a valorização dos professores. Esta contradição decorre da aplicação de noções de valorização esvaziadas de sentido axiológico, de modo que os critérios de reconhecimento do valor do professor estão relacionados ao cumprimento de prescrições externas sobre o seu trabalho e que resultam em recompensas na forma de remuneração, benefícios e progressão na carreira, articulados à cultura do desempenho e da performance considerada mais adequada às legislações estatais. Identificamos nas legislações federais do período de 1988 a 2014 uma ardilosa apropriação do termo "valorização", que obscureceu a dimensão axiológica que tem no reconhecimento social da categoria de professores do ensino básico - pela sua função social, seus saberes técnicos, teóricos e experienciais - os fundamentos de valorização para além da garantia de salários, plano de carreira, assistência previdenciária e condições de trabalho, sendo necessária a superação deste entendimento e a compreensão de que os problemas enfrentados pelos professores são inerentes às condições de trabalho do modo de produção capitalista, sendo fundamental reiterar que a luta pela valorização, não só do trabalho dos professores, mas de todas as categorias profissionais, sempre se dará dentro dos limites de relações de exploração no modo de produção capitalista.
\end{abstract}

Palavras-chave: Educação e Estado. Trabalho docente. Política educacional. Valor.

\begin{abstract}
The objective of this article was to obtain the notions of valorization of the work of the teacher present in the federal educational policies. We have done bibliographic and documentary studies about the theoretical reference on historical and dialectical materialism. The devaluation found in the school daily life and on those that materialize the educational practice contradicts the educational policies that was supposed to aim for the appreciation of the teachers. This contradiction arises from the application of notions devoid of axiological meaning, so that the criteria for recognition on the value of the teacher are related to the fulfillment of external prescriptions about his or her work and that results in rewards in the form of remuneration, benefits and career progression, articulated in the culture of performance and the work that is considered more adequate to state legislations. We have identified in the federal legislations from 1988 to 2014 a cunning appropriation of the term "valorization", which obscured the axiological dimension of social recognition on this category of primary school teachers - by their social function, their technical skills, theoretical and experiential roles - the fundamentals of valorization beyond wage contracts, career plan, social security and working conditions, it being necessary to surpassing this understanding and the comprehension that the problems faced by teachers are inherent to the working conditions of the capitalist way of production, and it is fundamental to reiterate that the struggle to effective valorization not only of the work of teachers but of all professional categories always will be inside of the limits of exploration relations in the capitalist way of production.
\end{abstract}

Keywords: Education and State. Teacher's work. Educational policy. Value.

\footnotetext{
* Pedagogo (UFSCar) e Mestre em Educação (PPGE/UNESP Rio Claro). E-mail: rob.edu@tutamail.com

** Pedagoga (UNESP), Mestre em Fundamentos da Educação (UFSCar), Doutora em Educação (UNICAMP), docente no Departamento de Educação e no PPGE da UNESP (Rio Claro) e coordenadora do GPEMEC. E-mail: aurea.costa@unesp.br
} 


\section{Introdução}

As reivindicações dos professores por medidas efetivas de valorização remontam à Constituinte do Império, na década de 1820. Para o recorte do presente artigo, não é demais retomar que a expansão do ensino de primeiro grau imposta pelo regime civil-militar com as reformas de 1968 e de 1971, no que diz respeito aos professores, resultou na intensificação de seu trabalho e no rebaixamento salarial até hoje não revertido (MONLEVADE, 2000). Se por um lado, houve a massificação do atendimento escolar no ensino básico, naquela conjuntura, por outro, não houve ampliação na aplicação de recursos para esse fim, de modo que essa política foi consolidada às custas da intensificação e da precarização do trabalho docente, não sem resistências, pois "Os baixos salários e as péssimas condições de trabalho levaram os/as docentes a organizarem-se contra o arrocho salarial e pela melhoria da educação, através de associações, sindicatos, fóruns, etc." (ROCHA, 2009, p. 26).

Da Constituição da República Federativa do Brasil de 1988 (CF/88) ao Plano Nacional de Educação (PNE) 2014-2024, a pauta da valorização do trabalho do professor figurou em praticamente todas as políticas educacionais, motivo pelo qual a noção de valorização do trabalho docente guarda uma contradição que tem sido objeto de reflexões sob diferentes aspectos, tais como do financiamento, em que foi avaliada a relação entre a valorização docente e a qualidade do ensino a partir do Fundo de Manutenção e Desenvolvimento do Ensino Fundamental e Valorização do Magistério (Fundef) (RAMOS, 2008); ou a questão remuneratória, referente à Lei do Piso Salarial Profissional Nacional (PSPN) para os professores, focando o papel dos partidos, do Governo Federal e da Confederação Nacional dos Trabalhadores em Educação (CNTE), no Congresso Nacional, durante sua tramitação (VIEIRA, 2013); e, ainda, estudos que dão um panorama da produção acadêmica sobre essa noção de valorização nas políticas educacionais entre 1999 e 2009, situando-a no contexto da crise estrutural do sistema do capital, que se constitui em excelente material (BERLATTO, 2011). Dentre todos, o que mais nos instigou para refletir sobre critérios de valorização foi o trabalho de Facci (2004) sobre a especificidade pedagógica do trabalho docente, cuja pesquisa nos chamou a atenção para o desafio de se discutir a reivindicação de políticas de valorização do professor fundamentadas no reconhecimento social, na autonomia, no savoir-faire. Nos indagamos, portanto, se a valorização requer para além das garantias de salário e carreira, também a liberdade de cátedra, a autonomia pedagógica e a efetiva participação nas decisões sobre as políticas educacionais, dando ao professor poderes consultivos e deliberativos sobre os rumos da educação escolar brasileira.

Este artigo objetiva demonstrar que as noções de valorização presentes nas principais políticas balizadoras da educação no país reduziram o debate à sua dimensão econômica, assim como buscaram alicerçar medidas de controle sobre o trabalho do professor, descaracterizando o sentido axiológico do termo e problematizando a tendência imediata ao afirmar que a valorização do trabalho dos professores consiste em garantir-lhes adequados salários, bem 
como condições de trabalho e formação condizentes com as demandas profissionais, uma vez que os salários, as condições de trabalho e a formação correspondem tão somente às dimensões econômicas limitadas pelo antagonismo essencial entre capital e trabalho e, portanto, dizem respeito aos conflitos inerentes à venda e condições de usufruto da força de trabalho, reduzindo o entendimento sobre a atribuição de valor. Para tal, procedemos à análise documental do conteúdo de oito legislações federais desde a Constituição Federal de 1988, até o Plano Nacional de Educação 2014-2024, com ênfase na forma como apresentou-se a noção de valorização.

O texto se estrutura nesta introdução, em uma breve síntese teórica que fundamenta as hipóteses e a problematização, em dois subitens referentes à análise da legislação federal em dois momentos, um imediatamente após o processo de redemocratização do país, momento de esperança na recuperação das instituições democráticas como estratégia de ampliação de direitos, frustrada pela implantação da reforma do Estado neoliberal; e outro na conjuntura de governos populares, em que se esperava que o protagonismo do Partido dos Trabalhadores no Governo Federal trouxesse uma significativa recuperação dos direitos destituídos no período anterior, culminando com uma síntese do nosso entendimento sobre o tema nas considerações finais.

\section{Docência: um trabalho de valor}

As pesquisas têm demonstrado que a noção de valorização docente não alcança o estatuto de conceito, devido ao fato de se referir a um fenômeno que nasce como resposta às reações da classe trabalhadora mediante um real processo de abstração e atribuição de baixos valores ao trabalho humano em geral. No âmbito desse complexo, surgem análises de aspectos imediatamente econômicos, como salário e vantagens; aspectos mediatamente econômico-corporativos, como direitos e benefícios, e aspectos axiológicos, que se referem ao reconhecimento da função social do professor, nos processos de humanização dos seres humanos, que envolvem não só o estatuto, mas as condições de trabalho e de vida desses profissionais. Somente investigando todos os aspectos desse fenômeno concreto será possível, por meio de um esforço conjunto, atravessar a pseudoconcreticidade (KOSIK, 1976) e atingir o âmago da questão: é possível valorizar o trabalho docente no modo e produção capitalista? O valor do trabalho docente é mensurável?

Não é possível analisar a valorização sem considerar o seu anverso, que é a desvalorização. Compartilhamos a hipótese de que desde o século XIX (VILLELA, 2003) o Estado tem constituído dispositivos de controle do professor sob a lógica da recompensa mediante a obediência, a renúncia de direitos, a dedicação abnegada e a resiliência, e não sua valorização. De fato, o reconhecimento do trabalho do professor inclui salários dignos, contratos e condições de trabalho adequadas, estabilidade no emprego, plano de carreira, previdência, jornada reduzida com tempo para preparo das aulas, poucos alunos em sala de aula, formação condizente com a formulação de respostas e metodologias que garantam o aprendizado e a educação de qualidade 
aos educandos, reconhecimento social, liberdade de cátedra e outros elementos objetivos, demonstrando a complexidade da questão e compreendendo um conjunto de medidas dependentes do aparelho do Estado para serem concretizados sob a forma de políticas com impacto na categoria e em cada professor individualmente, envolvendo aspectos materiais e simbólicos, imediatos e mediatos (VIEIRA, 2013). Dessa forma, quem estabelece o valor do professor e os critérios para tal valorização é o "Estado-contratante", por vezes convertendo-se em mais uma forma para o controle do trabalho docente, pelo mecanismo da recompensa dos professores que respondem aos requisitos desejados.

Se os salários dizem respeito ao pagamento da força de trabalho vendida pelo trabalhador, cuja função é possibilitar que esta força de trabalho se mantenha viva, se reproduza e consiga retornar continuamente ao seu posto de trabalho, então, tomar o salário como referência para a valorização constitui-se numa redução economicista.

Da mesma forma, a melhoria nas condições de trabalho diz respeito tão somente à garantia de que a venda da força de trabalho se realize reduzindo-se os níveis de morbidade, o que consiste em ponto de tensionamento entre capital e trabalho, projetado como tensionamento entre os governos e o professor, funcionário público, que mesmo sem ser objeto de extração da mais-valia é objeto de opressão e exploração.

Em países com profundas desigualdades sociais e econômicas, com desigual distribuição da renda, como o Brasil, o rebaixamento salarial chega a ameaçar o provimento da sobrevivência a um contingente significativo de professores que, para complementarem a renda, se submetem a jornadas de até 60 horas semanais, cuja situação contribui para o adoecimento, o rebaixamento da capacidade de trabalho da categoria, bem como a perda de qualidade da educação. Assim, as disputas em torno do salário dos professores evidenciam a sua desvalorização, uma vez que o histórico arrocho salarial no Brasil tem resultado em empobrecimento, adoecimento e interdição de acesso aos bens culturais, uma das "matérias-primas" de seu fazer pedagógico. Disso podemos estabelecer como hipótese que se dá uma relação dialética do tipo valorização-desvalorização do professor, expressa na forma da lei como uma noção polissêmica de valorização, cujo conteúdo varia, servindo, antes, como retórica - para a aplicação de um severo regime de controle do trabalho docente e redução ao trabalho abstrato, destituindo-o de autonomia -, do que como reconhecimento da importância e da especificidade de sua função social.

No modo de produção capitalista, o trabalho docente tende a ser reduzido a trabalho abstrato, cujo valor é aprisionado à dimensão do preço por quantum de trabalho, abstraindo-se de seus aspectos qualitativos objetivos e subjetivos (MARX, 2013). Neste modo de produção, o trabalho não tem valor per si no sentido do reconhecimento de sua função social do sujeito trabalhador como sujeito político capaz de transformar a realidade, mas assume valor quantitativo, em função de horas trabalhadas, independentemente do tipo de atividade, cuja atribuição de preço se dá a partir dos critérios da classe que detém o domínio econômico e a direção política da sociedade, conforme a lógica da oferta e da procura, independentemente 
do valor substantivo do trabalho. Diante de tal realidade, os governos administram a disputa interclassista pelos critérios de valorização do trabalho por meio do rebaixamento e do esvaziamento dos conteúdos do trabalho do professor - em poucas palavras, aprofundando o processo de alienação, que consiste na destituição do controle e dos conteúdos do trabalho, bem como nas relações estranhadas com o objeto de trabalho, tornando-os mais vulneráveis à ação reguladora das políticas educacionais.

Uma remuneração que possibilite a vida digna é condição mínima, mas não suficiente, para a valorização do trabalho. No caso dos docentes, a luta pelo preço da hora de trabalho é parte da luta pela valorização da categoria docente no capitalismo e da própria educação, mas, ainda que conquistem altos salários, isso não suprime as outras dimensões, como as condições de trabalho, a perda de autonomia e a liberdade de cátedra.

Nas atividades laborais complexas como a docência, demanda-se custos de formação mais altos, mas, apesar disso, a categoria docente tem sofrido as mesmas injunções pela performatividade e produtividade que trabalhadores da produção de bens materiais. $\mathrm{O}$ capital persegue o controle sobre os critérios de atribuição de qualidade ao trabalhador de acordo com seus fins, do perfil requisitado, em vez de reconhecer e remunerar os trabalhadores a partir de seus conhecimentos técnicos, experiência profissional e função social.

Os diversos governos possuem clareza e coerência de objetivos quando se trata dos cursos de formação de professores, seja inicial ou continuada, cujas concepções pedagógicas estão alinhadas às determinações dos organismos internacionais que orientam a economia e política dos países considerados em desenvolvimento, submetendo-as às demandas educacionais articuladas diretamente à preparação dos trabalhadores para se adaptarem aos processos de acumulação e reprodução do capital. Se, por um lado, a oportunidade de formação em serviço, na forma de uma política pública de cursos gratuitos de formação, é uma reivindicação histórica da categoria, por outro, os governos têm apresentado tal formação como forma de valorização, oferecendo cursos que conformam um determinado perfil profissional já prescrito pelo âmbito governamental, tratando-se de ponto de tensionamento e disputa ideológica, pois os professores necessitam de formação que os enriqueça e prepare para enfrentar as vicissitudes do trabalho, fortalecendo sua autonomia pedagógica, em vez de destituí-la a partir de ações formativas implementadas verticalmente.

O capital luta para aniquilar as diferenças do trabalho específico e concreto realizado por cada trabalhador, transformando-o em trabalho geral-abstrato para, assim, estabelecer a medida de valor correspondente a cada processo produtivo (MARX, 2013). O Estado, por meio de seus sucessivos governos, tem perseguido o objetivo de abstrair a especificidade do trabalho docente por meio de estratégias, como a criação de mecanismos de aferição de produtividade baseados no fluxo do produto - estudantes certificados, a vinculação da remuneração ao desempenho e à produtividade, a instituição de mecanismos de comparação e competitividade entre os docentes, o tratamento do absenteísmo sob os mesmos critérios que se trata este fenômeno no mundo 
fabril, desconsiderando o tipo específico de desgaste do professor, subtraindo a necessidade do professor de estar em constante processo de formação como parte dos atos de trabalho e que devem ser remunerados, sendo compreendidos como questão privada do professor, entre outros. Facci (2004) aponta que a valorização relacionada ao processo de trabalho do professor, e a correspondente concepção pedagógica que o orienta, tem importância significativa, mas não pode ser tomada isoladamente. Entendemos ser necessária a problematização da noção de valorização a partir das constatações de Facci (2004) e da superação das limitações das demais dimensões a ele associadas, tais como salário, condições de trabalho e formação.

\section{Tempo de esperança: a conjuntura política da redemocratização brasileira e as políticas federais para os docentes do ensino básico}

A crescente organização e mobilização dos professores na década de 1980 possibilitou a eleição de seus representantes para a Assembleia Nacional Constituinte, a ponto de garantir no texto da $\mathrm{CF} / 88$ propostas políticas relacionadas à valorização dos profissionais da educação, com estatuto de princípios que se referem à autonomia, às condições de trabalho e carreira e à participação na gestão da escola:

\footnotetext{
Art. 206. O ensino será ministrado com base nos seguintes princípios: (EC n. ${ }^{\circ}$ 19/1998 e EC n. $\left.{ }^{\circ} 53 / 2006\right)[\ldots]$

II - liberdade de aprender, ensinar, pesquisar e divulgar o pensamento, a arte e o saber; III - pluralismo de ideias e de concepções pedagógicas, e coexistência de instituições públicas e privadas de ensino; [...]

V - valorização dos profissionais da educação escolar, garantidos, na forma da lei, planos de carreira, com ingresso exclusivamente por concurso público de provas e títulos, aos das redes públicas;

VI - gestão democrática do ensino público, na forma da lei; [...]

VIII - piso salarial profissional nacional para os profissionais da educação escolar pública, nos termos de lei federal.

Parágrafo único. A lei disporá sobre as categorias de trabalhadores considerados profissionais da educação básica e sobre a fixação de prazo para a elaboração ou adequação de seus planos de carreira, no âmbito da União, dos Estados, do Distrito Federal e dos Municípios. (BRASIL, 1988, p. 121).
}

O texto aprovado na $\mathrm{CF} / 1988$ não continha o adjetivo "nacional" relacionado ao piso salarial, o que se deu apenas em 2006, através da Emenda Constitucional n. 53 (BRASIL, 2006) que, entre outros, também criou o Fundo de Manutenção e Desenvolvimento da Educação Básica e de Valorização dos Profissionais da Educação (Fundeb) (BRASIL, 2007).

Verificamos uma noção de valorização que é enunciação genérica, intenção, promessa, coerente com o caráter minimalista do texto, ainda que apresente a necessidade de planos de carreiras que assegurem concursos públicos e o piso salarial. Apesar do estatuto de "princípio", apresenta uma noção de valorização relacionada ao aspecto remuneratório. Por não se tratar de uma lei especificamente educacional, não detalha os pressupostos ou diretrizes que possibilitem 
um entendimento mais apurado, mas reconhece uma autonomia do professor de ensinar e fazer suas escolhas pedagógicas, o que condiz com aquele momento de valorização da democracia representativa.

A ascensão do projeto neoliberal no Brasil como política de Estado se deu em 1990. Em 1996, neste contexto, foi aprovado pelo Congresso Nacional (CN) a Lei de Diretrizes e Bases da Educação Nacional (LDB) (BRASIL, 1996a), tendo prevalecido, nas disputas que se deram em torno do projeto, as propostas que imputaram à referida lei um caráter alinhado ao neoliberalismo. A recomendação quanto à valorização dos profissionais da educação se concretizou na forma de regulamentação mais detalhada do ingresso por concurso público, da proposição de piso salarial e de plano de carreira, retomados do texto da CF, tendo sido acrescido à noção de valorização o aperfeiçoamento profissional continuado, a progressão por titulação, habilitação e por avaliação de desempenho e plano de carreira, a regulamentação da jornada semanal, com tempo para estudos, planejamento e avaliação, e condições de trabalho, segundo as diretivas de cada sistema de ensino (BRASIL, 1996a). Nos incisos I, II, e IV, a noção de valorização do trabalho tem caráter retribuitório dos esforços individuais do professor, cabendo-lhe o preparo para as seleções realizadas via concurso público e o investimento em cursos e estudos no seu tempo extrajornada, tanto para aperfeiçoamento profissional como para obtenção de títulos para progressão na carreira vinculada à avaliação de desempenho, uma vez que a letra da lei carece do reconhecimento social da categoria como protagonista no processo de ensino na escola, agente civilizadora. Em vez disso, a valorização é condicionada ao cumprimento de requisitos pelo professor-indivíduo. Nenhum professor tem, numa perspectiva axiológica, valor a priori pela responsabilidade que assume e pela função social que cumpre, mas somente se cumprir as exigências de formação e provar desempenho. Trata-se, antes, de um mecanismo de prescrição de perfil desejável, associado a recompensas, numa conjuntura de real desvalorização na qual os professores se encontram, muitas vezes impossibilitados do cumprimento das exigências prescritas. Nos incisos III, V e VI, assim como no II parcialmente, a valorização dos profissionais da educação se relaciona às determinações estabelecidas pelos governos, por meio de leis e decretos (definição de afastamentos, salários, composição da jornada de trabalho e condições de trabalho). Ao nos debruçarmos sobre as atribuições das tarefas aos professores que constam na LDB, constatamos que ao mesmo tempo em que os educadores passaram a poder participar na instância deliberativa máxima da escola, também lhe foram incumbidas outras tarefas, como a articulação entre escola e comunidade, tendo sido relativizada sua principal atribuição: o ensino. Há, na principal lei que orienta os sistemas de educação no país, o esvaziamento daquela que consideramos a principal atribuição do professor e um alinhamento ao ideário construtivista, no qual ao professor cabe apenas “[...] zelar pela aprendizagem dos alunos [...]" (BRASIL, 1996a, p. 6).

Portanto, a noção de valorização expressa na $\mathrm{LDB}$, alicerçada nos pressupostos legais anunciados desde a CF de 1988 e considerado o contexto neoliberal da década de 1990, mescla 
a prescrição de exigências relacionadas à formação, com a enunciação de condições objetivas adequadas, além de estar relacionada ao esvaziamento do conteúdo do seu trabalho e à atribuição de novas responsabilidades - dentre as quais a de garantir a qualidade da educação, independentemente das condições objetivas para isso.

$\mathrm{Na}$ análise sobre o Fundo de Manutenção e Desenvolvimento do Ensino Fundamental e de Valorização do Magistério (Fundef) (BRASIL, 1996b, 1996c) foi constatado por Ramos (2008) um descompasso entre a ideia de valorização, relacionada ao valor aclamado ao professor, e aquilo que chamou de valorização efetiva, relacionada ao que se propôs oficialmente no Fundo. Prevaleceu a valorização em termos de remuneração e dentro dos marcos econômicos dados, a partir dos quais o Fundef operou equilibrando as reconhecidas desigualdades salariais existentes, de forma redistributiva. O fundo não definiu um PSPN e uso do amplo termo "remuneração", associado ao termo "condigno", relativo a merecimento, direcionava uma noção de valorização individualizada, não centrada no conjunto da categoria. Constatamos ter ocorrido uma apropriação ardilosa do termo valorização, pois foi posto na nomenclatura do fundo ao mesmo tempo em que foi esvaziado de sentido, tendo sido reduzido à dimensão remuneratória redistributiva, aquém até mesmo das vagas noções dadas na CF de 1988 e na LDB de 1996. No Fundo de Manutenção e Desenvolvimento da Educação Básica e de Valorização dos Profissionais da Educação (Fundeb), por sua vez, não houve significativa mudança em relação à noção presente no Fundef, na qual persistiu a noção de valorização sob o aspecto remuneratório de forma redistributiva. A apropriação ardilosa do termo por parte do governo Fernando Henrique Cardoso foi mantida pelo governo Lula, que conservou a valorização na nomenclatura do fundo, preservou seu sentido esvaziado e deu continuidade ao entendimento da questão remuneratória vinculada ao mérito do professor individualmente.

O primeiro Plano Nacional de Educação, aprovado no último ano do mandato de Fernando Henrique Cardoso, é considerado a principal lei decorrente da LDB, dado seu caráter global que objetivava a organização da educação nacional a partir de metas e objetivos a serem realizados nos dez anos seguintes ao de sua aprovação (HERMIDA, 2006; MOURA, 2015). Duas propostas antagônicas de plano disputaram o processo de elaboração na década de 1990: em uma, a proposta do Executivo, se expressavam os interesses do capital internacional e da ideologia das classes dominantes, pautados pela centralização na elaboração e tomada de decisões, na redução do papel do Estado com a manutenção e desenvolvimento da educação; na outra, elaborada pelos movimentos sociais organizados ${ }^{1}$, estava expresso o projeto democrático e popular, a defesa da escola pública, com democratização da gestão, universalização da educação básica

1 O I Congresso Nacional de Educação (I CONED), realizado em 1996, em Belo Horizonte, Minas Gerais, retomou as pautas do Fórum Nacional em Defesa da Escola Pública e assumiu a tarefa de elaborar uma proposta de plano nacional de educação que se contrapusesse ao modelo educativo vigente. O II CONED, realizado, em 1997, também na capital mineira, sintetizou os debates ocorridos por todo o país no período anterior e elaborou um projeto alternativo intitulado de "Plano Nacional de Educação - proposta da sociedade brasileira" -, considerado contrário ao projeto hegemônico de educação que havia sido consagrado na LDB de 1996. 
e proposta de investimento de $10 \%$ do Produto Interno Bruto (PIB) na educação ao término da vigência do plano (contra os aproximados $4 \%$ que eram destinados na segunda metade da década de $1990^{2}$ ), além da reivindicação de implementação do Sistema Nacional de Educação. Depois de realizadas dezesseis audiências, o relatório final (Relatório Marchezan) descartou o projeto dos movimentos sociais, tendo a proposta do Executivo sido tomada como referência. No que diz respeito à valorização dos professores no PNE sancionado, o capítulo IV - intitulado Magistério da Educação Básica - tratou especificamente da questão, havendo ainda outras metas e considerações no restante do texto. A partir de quatro metas gerais apresentadas na Introdução, o texto aprovado elegeu cinco prioridades, tendo em vista que "[...] os recursos financeiros são limitados [...]" (BRASIL, 2001), dentre as quais destacamos a quarta:

4. Valorização dos profissionais da educação. Particular atenção deverá ser dada à formação inicial e continuada, em especial dos professores. Faz parte dessa valorização a garantia das condições adequadas de trabalho, entre elas o tempo para estudo e preparação das aulas, salário digno, com piso salarial e carreira de magistério. (BRASIL, 2001).

Como vimos, a valorização era prioritária no plano e se referia à formação inicial e continuada, às condições adequadas de trabalho, ao piso salarial e à carreira do magistério, com ênfase nos primeiros aspectos (formação inicial e continuada), os quais remetiam à melhoria na preparação dos profissionais para o trabalho. No item Diagnóstico do capítulo IV, dedicado ao Magistério da Educação Básica, o texto afirmou, dentre outros, que a melhoria da qualidade do ensino só seria possível se ocorresse a valorização do magistério e apresentou o entendimento da necessidade de uma política global, que envolvesse formação inicial, condições de trabalho, salário, carreira do magistério e formação continuada, pois muitos professores abandonaram a carreira devido à situação em que se encontravam as escolas e aos baixos salários, justificando a necessidade de se pensar políticas de estímulo aos docentes. Nas Diretrizes, constou que a qualificação dos professores era um dos maiores desafios para o plano e que "A implementação de políticas públicas de formação inicial e continuada dos profissionais da educação é uma condição e um meio para o avanço científico e tecnológico em nossa sociedade e, portanto, para o desenvolvimento do País." (BRASIL, 2001).

E na sequência afirmou que a valorização implicaria:

* uma formação profissional que assegure o desenvolvimento da pessoa do educador enquanto cidadão e profissional, o domínio dos conhecimentos objeto de trabalho com os alunos e dos métodos pedagógicos que promovam a aprendizagem;

* um sistema de educação continuada que permita ao professor um crescimento constante de seu domínio sobre a cultura letrada, dentro de uma visão crítica e da perspectiva de um novo humanismo;

2Castro (2007, p. 867) apresenta os seguintes dados referentes aos gastos totais em educação em relação ao PIB: 4,01\% em 1995, 3,92\% em 1996, 3,63\% em 1997, 4,13\% em 1998, 4,06\% em 1999 e $4 \%$ em 2000. 


\footnotetext{
* jornada de trabalho organizada de acordo com a jornada dos alunos, concentrada num único estabelecimento de ensino e que inclua o tempo necessário para as atividades complementares ao trabalho em sala de aula;

* salário condigno, competitivo, no mercado de trabalho, com outras ocupações que requerem nível equivalente de formação;

* compromisso social e político do magistério. (BRASIL, 2001).
}

Vinte e oito foram as metas aprovadas e que se relacionavam à valorização dos profissionais da educação propostas pelo capítulo IV, sendo que uma meta foi vetada (meta 4), pelo Presidente Fernando Henrique Cardoso, que dizia respeito ao piso salarial e aos planos de carreira (meta 1), duas metas eram relacionadas às condições de trabalho (metas 2 e 3), vinte e três metas diziam respeito à formação inicial e continuada (metas 5 a 27) e uma meta era de caráter amplo (meta 28). Uma análise detalhada pode ser conferida no trabalho de Rodrigues (2013). Tal como na LDB, no PNE 2001-2010, a noção de valorização esteve pautada no contexto neoliberal da década de 1990, por meio da confluência entre as exigências relacionadas à formação, às condições objetivas consideradas adequadas e à remuneração condigna.

\section{Tempo de espera: a valorização docente nas legislações federais dos governos do Partido dos Trabalhadores}

Se em 1988 se vivia um clima de renovação de esperanças na democracia, na liberdade, nos direitos civis, políticos e sociais, em vista do fim do período ditatorial, a vitória de Luís Inácio Lula da Silva, nas eleições de 2001, levava à retomada das expectativas de valorização dos direitos dos trabalhadores, a partir do pressuposto de que, a partir daquele momento, o Brasil passaria a ser governado por um operário, vinculado a um partido popular, do qual se poderia esperar algum tipo de avanço nos direitos do trabalho e uma melhoria nas políticas de distribuição de renda.

No que tange à categoria docente, a espera pelo estabelecimento do PSPN foi de dez anos até sua efetiva vigência. Esse direito, incorporado no texto da CF de 1988 e da LDB de 1996, começou a ganhar forma de política pública no segundo mandato de Lula, com a Emenda Constitucional n. ${ }^{\circ}$ 53, que acrescentou o "nacional" ao texto inicial da CF e, ao ter criado o Fundeb, determinou prazo para elaboração de um projeto de lei que viesse fixar o PSPN, o que ocorreu com a aprovação da Lei n. ${ }^{\circ} 11.738$, em 16 de julho de 2008, (BRASIL, 2008). Essa lei estabeleceu um vencimento básico para todos os sistemas de ensino por uma jornada semanal de 40 horas, com atualização anual, considerando a proporcionalidade dos vencimentos no caso de jornadas iniciais diferentes; que no máximo $2 / 3$ (dois terços) da carga horária devem ser dedicados a atividades com os estudantes, que compete à União a complementação ou cooperação técnica para que os entes federados cumpram a lei e que os planos de carreira e remuneração do magistério devem ser elaborados ou adequados de forma a garantir o pagamento do piso fixado. Dois artigos receberam veto presidencial: um 
que previa o estabelecimento retroativo para a vigência da lei e o outro que consideraria improbidade administrativa o descumprimento da lei.

Conforme Fernandes (2015), a lei entrou em vigor em 2011 após decisão favorável do Supremo Tribunal Federal (STF), pois havia sido alvo da Ação Direta de Inconstitucionalidade (ADI) n. ${ }^{\circ} 4.167$ movida pelos governadores do Ceará, Mato Grosso do Sul, Paraná, Santa Catarina e Rio Grande do Sul. Uma das contradições referentes à Lei do Piso diz respeito ao valor inicialmente fixado:

As discussões referentes ao piso em 1994 apresentava o valor de R\$ 300,00, o salário mínimo era $\mathrm{R} \$ 64,75$. O valor proposto, $\mathrm{R} \$ 300,00$ equivalia a 4.6 salários mínimos. Ao aprovar a Lei do PSPN em 2008 o valor do piso foi de R \$950,00 e o salário mínimo R\$ 415,00 . A perda calculada corresponde a 50\%, ou seja o PSPN passou a valer 2.3 SM. (FERNANDES, 2015, p. 61).

Em 2018 seu valor era de R\$2.455,35 (TEIXEIRA, 2018) e o valor do salário mínimo era de R\$ 954,00 (BRASIL, 2017), uma relação de 2.6, mantendo-se no patamar relacional de quando a lei foi aprovada em 2008.

Tanto o processo de votação quanto o de implementação da lei foram permeados por tensões, pois além das disputas que se deram no processo de tramitação e votação - que foram analisadas por Vieira (2013) -, e da ADI movida, muitos gestores se respaldaram na Lei de Responsabilidade Fiscal (LRF) para não cumprirem a Lei do Piso. Ainda hoje, pouco mais de uma década após a lei ter sido aprovada, é significativo o número de entes federados que não cumprem a Lei do Piso, seja no que diz respeito ao valor fixado, seja na atribuição de carga horária, que estipula um terço da jornada para atividades extraclasse, conforme demonstra o levantamento realizado pela CNTE (2019). Ainda que não seja o único aspecto relacionado à valorização, não podemos desconsiderar o peso da questão salarial, pois:

Dentre as implicações dos baixos salários para a profissão docente, destaca-se a baixa atratividade e o intenso processo de perda de prestígio e status social que o magistério continua enfrentando nas últimas décadas. Tais implicações afetam tanto a profissão docente quanto o professor como sujeito e podem ser explicadas pela intensa jornada de trabalho. Existe uma variedade nas horas trabalhadas pelos professores de acordo com o nível de ensino e com a região geográfica em que atua; todavia, as pesquisas apontam que muitas horas trabalhadas fora da escola não são remuneradas (FERNANDES, 2015, p. 64).

Outra questão diz respeito à possibilidade de os professores passarem a receber menos que o estipulado na lei ao se aposentarem ${ }^{3}$, pois não há garantia de isonomia salarial entre os

3 Está em curso no país uma Reforma da Previdência que, pela proposta do Executivo, estabelecerá a idade mínima de 60 anos para professores e professoras se aposentarem desde que completem 30 anos de contribuição. Atualmente, não há idade mínima, mas sim a necessidade de que as professoras tenham contribuído por 25 anos e os professores 30 anos. 
professores da ativa e os que se aposentam (FERNANDES, 2015). Vieira (2013, p. 20), por sua vez, ponderou que "embora se constitua em uma mudança na realidade salarial dos profissionais da educação, sua implantação não interfere na lógica do modelo capitalista. Permite, contudo, a emergência de lutas socialmente articuladas, orientadas em outras perspectivas".

Isto demonstra uma das contradições referentes à lei, mas, o fato de ter sido aprovada como peça jurídica regulatória, não nos permite afirmar que se configurou como mudança na realidade salarial porque a realidade concreta é muito mais ampla que sua esfera legal e no caso em questão diz respeito à totalidade dos sistemas de ensino, pois a lei aprovada possui este caráter normatizador para todo o país.

Quanto à noção de valorização, depreendemos aquele esvaziamento de significado relativo à sua redução à dimensão salarial já presente nas noções dos Fundef e Fundeb, com a diferença que o termo não consta no texto da lei e que há o ponto sobre a limitação de $2 / 3$ (dois terços) da jornada para atividades com os estudantes. Faz-se necessária a luta orientada na perspectiva de exigência de seu cumprimento, embora sua noção de valorização seja esvaziada e a lei permaneça até hoje quase como letra morta.

Com vistas à elaboração do segundo Plano Nacional de Educação, o Governo Federal assumiu o compromisso, no final da Conferência Nacional da Educação Básica (CONEB), ocorrida em 2008, de realizar uma Conferência Nacional de Educação (CONAE) em 2010, devendo esta ser precedida por etapas municipais e estaduais. Foram destinados à realização da Conferência em todas as suas etapas R 32 milhões, tendo sido constituída pelo MEC uma comissão com trinta e cinco entidades para coordenar, promover e monitorar todo o processo. As etapas municipais foram realizadas no primeiro semestre e as etapas estaduais foram realizadas no segundo semestre de 2009. A definição da metodologia, do tema central, dos eixos temáticos, colóquios e da dinâmica ficou sob a responsabilidade da Comissão Especial de Dinâmica e Sistematização (CEDS), composta por dez integrantes de dez entidades (SEB, UNE, CONTEE, CONSED, ANDIFES, Campanha Nacional pelo Direito à Educação, CONIF, CNE, UNDIME e ABRUC) (SOUZA, 2012; SILVA, 2014; MOURA, 2015).

Foram estabelecidos seis eixos temáticos dentre os quais figurou a Formação e Valorização dos Profissionais da Educação, Eixo IV (BRASIL, 2010a). Foram realizadas 1.891 conferências municipais ou intermunicipais, 27 estaduais e do Distrito Federal e 336 conferências livres, em escolas, universidades e outras organizações da sociedade civil, sendo que 3.889 pessoas, das quais 2.416 eram delegados, participaram da etapa nacional, realizada em Brasília, entre 28 de março e $1^{\circ}$ de abril de 2010 (SOUZA, 2012). No Documento Final, constatamos que a noção de valorização relacionou sobremaneira a dimensão da formação - em especial a continuada como elemento para a valorização do trabalho do professor. É ao mesmo tempo abrangente, a partir do detalhamento de aspectos relacionados às condições de trabalho, salários e plano de carreira, operando dentro da lógica reivindicatória de melhorias das condições dadas. 
Das noções que vimos é a mais abrangente, todavia só nos serve como registro histórico do que foi debatido e deliberado, pois há de se considerar que o amplo debate realizado, expresso na abrangência de questões abordadas no Documento Final, não foi considerado pelo Governo Federal como se esperava (SOUZA, 2012), quando este deu entrada no Congresso Nacional no Projeto de Lei (PL) n. ${ }^{\circ}$ 8.035/2010 (BRASIL, 2010b), que versava sobre o novo Plano Nacional de Educação.

Moura (2015), ao reproduzir as palavras de Francisco Chagas, Secretário Executivo Adjunto do MEC e Coordenador da CONAE, destacou que, "[...] a abertura de um espaço propositivo, com participação e capilaridade, não criou necessariamente uma obrigação do Executivo quanto ao acatamento das deliberações aprovadas pela Conferência." (MOURA, 2015, p. 91). Tendo sido a CONAE convocada e realizada com o intuito de ouvir a sociedade organizada para a elaboração do novo PNE, nada menos poderia se esperar no sentido de que fosse proposto um PNE que incorporasse as deliberações realizadas.

Dentre as dez diretrizes apontadas no Plano Nacional de Educação 2014-2024, a nona consistiu na “[...] valorização dos (as) profissionais da educação [...]" (BRASIL, 2014). O plano foi estruturado a partir de vinte metas e de diversas estratégias relacionadas a cada uma delas, dentre as quais podemos considerar como sendo relacionadas à valorização as metas 15, 16, 17 e 18, destacadas a seguir:

[...] Meta 15: garantir, em regime de colaboração entre a União, os Estados, o Distrito Federal e os Municípios, no prazo de 1 (um) ano de vigência deste PNE, política nacional de formação dos profissionais da educação de que tratam os incisos I, II e III do caput do art. 61 da Lei no 9.394, de 20 de dezembro de 1996, assegurado que todos os professores e as professoras da educação básica possuam formação específica de nível superior, obtida em curso de licenciatura na área de conhecimento em que atuam. [...] Meta 16: formar, em nível de pós-graduação, 50\% (cinquenta por cento) dos professores da educação básica, até o último ano de vigência deste PNE, e garantir a todos (as) os (as) profissionais da educação básica formação continuada em sua área de atuação, considerando as necessidades, demandas e contextualizações dos sistemas de ensino. [...] Meta 17: valorizar os (as) profissionais do magistério das redes públicas de educação básica de forma a equiparar seu rendimento médio ao dos (as) demais profissionais com escolaridade equivalente, até o final do sexto ano de vigência deste PNE. [...]

Meta 18: assegurar, no prazo de 2 (dois) anos, a existência de planos de Carreira para os (as) profissionais da educação básica e superior pública de todos os sistemas de ensino e, para o plano de Carreira dos (as) profissionais da educação básica pública, tomar como referência o piso salarial nacional profissional, definido em lei federal, nos termos do inciso VIII do art. 206 da Constituição Federal. [...] (BRASIL, 2014).

As metas 15 e 16 dizem respeito à formação inicial e continuada e as metas 17 e 18 dizem respeito ao salário e aos planos de carreiras, sendo que a meta 18 não é restrita aos professores. A ênfase dada à formação e valorização dos professores apontada por Moura (2015) deve-se a que estas quatro metas juntas correspondem a vinte por cento do total de metas do plano. Sob este aspecto, consideramos que houve um prejuízo ao reduzir a estrutura geral do plano para vinte 
metas, pois as deliberações da CONAE referentes à valorização dos professores não puderam ser contempladas no plano aprovado.

Uma primeira questão a ser destacada é que as metas 15 e 18 estabelecem como objetivo o cumprimento de um artigo da LDB de 1996 e de um artigo da CF de 1988 respectivamente. Tal como aconteceu no PNE2001-2010, estabeleceu-se como planejamento estratégico o cumprimento de questões já abordadas em leis anteriores. Após anos de debates e disputas na elaboração da lei, constatamos duas metas que nada mais fazem que colocar mais prazo para o cumprimento de artigos de leis máximas do país, ainda mais na condição de reedições sintetizadas de metas que já constaram no PNE 2001-2010 (metas 1, 5, 7, 12, 13, 15, 17, 18 e 19 do capítulo IV, cf. BRASIL, 2001), demonstrando a falência das legislações anteriores. A meta 16 também é uma reedição sintetizada das metas 23 e 24 do capítulo IV do PNE 2001-2010 (BRASIL, 2001), estabelecendo agora um percentual mínimo de professores a obterem a formação estipulada ao término da vigência do plano. As estratégias relacionadas à meta são vagas e não estabelecem condições reais dos professores realizarem a formação desejada, embora amplamente discutidas no CONAE.

A meta 17 aborda uma questão fundamental e que vem a constar em uma lei federal pela primeira vez, ao propor equiparação do rendimento médio dos profissionais do magistério às demais profissões com escolaridade equivalente. Entretanto, ainda que nas estratégias relacionadas faça referência ao piso salarial nacional profissional, desconsidera que este piso está abaixo do rendimento médio dos profissionais com escolaridade equivalente e, ainda assim, não é cumprido em muitos estados e municípios brasileiros. Considerando o conjunto de problemas relacionais ao plano, não podemos apontar como avanço a existência dessa meta, pois não vemos relação lógica e efetiva entra ela e as estratégias que a acompanham e o conjunto de metas do plano. Não se trata, todavia, de pensarmos de forma binária e afirmarmos, por oposição, que se trata de retrocesso, mas deve-se realizar uma análise que leve em conta o conjunto de metas e sua relação com o histórico das ações que propõe, assim como, fundamentalmente, a coerência entre o legislado e as ações cotidianas do Governo Federal e sua relação com o plano e demais leis já aprovadas.

Quanto à noção de valorização expressa no novo PNE, verificamos que continua alicerçada nos pressupostos do contexto neoliberal da década de 1990, ao mesclar exigências relacionadas à formação, com vagas indicações de condições objetivas consideradas adequadas e no entendimento da atribuição de valor relacionado ao aspecto da majoração remuneratória. Apontamos, por fim, que as conhecidas reivindicações de valorização reeditadas no atual Plano Nacional de Educação permanecerão na pauta dos movimentos organizados.

\section{Considerações finais}

Tanto na conjuntura imediatamente após o processo de redemocratização do país quanto no momento da espera por políticas populares, constatamos três tendências: uma de valorização fundada no perfil de professor estabelecido pelo Estado-contratante, estabelecido por critérios 
de cuja construção os professores foram alijados; outra de associação entre a ideia de valorização e a de recompensa, que remete, antes, ao controle, do que ao reconhecimento; e, por último, a chamada cultura de performatividade, que enfoca mais a produtividade individual dos professores, seja na formação continuada, seja na atuação, do que o reconhecimento social do conjunto da categoria. Essas três tendências constituem-se na materialidade concreta do processo dialético de valorização e desvalorização, evidenciada tanto nas políticas do primeiro período - que primaram pela focalização e o minimalismo desde a CF/88, a LDB, o Fundef, até o PNE/2001, em que se verificou tão somente a reprodução da mesma retórica vazia em cada lei, identificando-se alguma ampliação de direitos na LDB, como garantia de plano de carreira, concurso, participação na gestão da escola e no Fundef, que instituiu o bônus, apropriado para o controle do absenteísmo - quanto no segundo período, em legislações como o Fundeb, a lei do PSPN, o documento final do CONAE e o PNE de 2014, em que se consolidou definitivamente a formação continuada como política de valorização, abstraindo-se que proporcionar formação para melhoria de desempenho é uma estratégia associada ao controle do trabalho, não ao seu reconhecimento.

De 1988 a 2014 ocorreu uma apropriação ardilosa do termo valorização pelas sucessivas políticas educacionais que proclamavam melhorias para a docência, mas a vincularam às prescrições formativas e de responsabilização dos professores, reduzidas à dimensão econômica, servindo como instrumento de recompensa para a aplicação de um regime de controle do trabalho docente e sua redução ao trabalho abstrato, destituindo-o de autonomia, não vinculando a valorização ao reconhecimento da importância e da função social do professor. Instituir por lei a valorização e não a efetivar ou esvaziá-la de seu sentido são formas de neutralização de seus efeitos progressivos, que denunciam os limites das lutas restritas aos marcos institucionais, pois a contradição que se constata nas medidas parlamentares - quando se trata de legislar sobre interesses dos trabalhadores - são contradições inerentes ao modo de produção do capital e de suas instituições de sustentação.

Para a superação da noção de valorização como recompensa, nas formas salário, condições de trabalho e formação, é necessário compreender que os problemas enfrentados pelos professores são inerentes à concepção de educação e condições de trabalho do modo de produção capitalista, sendo fundamental que a luta pela superação deste modo de produção ocorra concomitantemente à luta para efetivação da valorização, não só do trabalho dos professores, mas de todo o trabalho no seu sentido de transformação da natureza e da sociedade em prol da satisfação de todas as necessidades humanas. Por mais que o trabalho docente tenha sido objeto de regulações, com ampliação de vantagens e benefícios, as disputas no âmbito da luta de classes acabam por corroer os ganhos proporcionados pela ampliação de direitos na esfera formal, o que consiste na contradição essencial do capitalismo e demanda a continuidade da luta por pautas democráticas pela preservação desses direitos e ampliação deles, como a luta pelo reconhecimento social do professor enquanto um importante sujeito social transformador da sociedade, sob a mediação da humanização dos sujeitos sociais. 


\section{Referências}

BERLATTO, Andréa Cristina. A valorização do trabalho do professor para além da remuneração. 2011. Dissertação (Mestrado em Educação) - Centro de Ciências da Educação, Universidade Federal de Santa Catarina, Florianópolis, 2011.

BRASIL. [Constituição (1988)]. Constituição da República Federativa do Brasil. 35. ed. Brasília: Câmara dos Deputados, Edições Câmara, 2012.

BRASIL. Lei n 9.394, de 20 de dezembro de 1996. Estabelece as diretrizes e bases da educação nacional. Diário Oficial da União. Brasília: Casa Civil, 1996a. Disponível em: <http://portal.mec.gov.br/seesp/arquivos/pdf/ lei9394_ldbn1.pdf>. Acesso em: 12 nov. 2016.

BRASIL. Emenda Constitucional n 14, de 12 de setembro de 1996. Modifica os artigos 34, 208, 211 e 212 da Constituição Federal e dá nova redação ao artigo 60 do Ato das Disposições Constitucionais Transitórias. Diário Oficial da União. Brasília: Casa Civil, 13 set. 1996b. Disponível em: <http://www.planalto. gov.br/ccivil_03/constituicao/ emendas/emc/emc14.htm>. Acesso em: 12 nov. 2016.

BRASIL. Lei no 9.424, de 24 de dezembro de 1996. Dispõe sobre o Fundo de Manutenção e Desenvolvimento do Ensino Fundamental e de Valorização do Magistério, na forma prevista no artigo $60, \S 7^{\circ}$, do Ato das Disposições Constitucionais Transitórias, e dá outras providências. Diário Oficial da União. Brasília: Casa Civil, 1996c. Disponível em: <http://www.planalto.gov.br/ccivil_03/leis/L9424.htm>. Acesso em: 12 nov. 2016.

BRASIL. Lei $\mathrm{n}^{\circ}$ 10.172, de 9 de janeiro de 2001. Aprova o Plano Nacional de Educação e dá outras providências. Diário Oficial da União. Brasília: Casa Civil, 2001.

BRASIL. Emenda Constitucional no 53, de 19 de dezembro de 2006. Dá nova redação aos artigos 7, 23, 30, 206, 208, 211 e 212 da Constituição Federal e ao artigo 60 do Ato das Disposições Constitucionais Transitórias. Diário Oficial da União. Brasília: Casa Civil, 2006. Disponível em: <http://www.planalto.gov. br/ccivil_03/constituicao/ emendas/emc/emc53.htm>. Acesso em: 12 nov. 2016.

BRASIL. Lei no 11.494, de 20 de junho de 2007. Regulamenta o Fundo de Manutenção e Desenvolvimento da Educação Básica e de Valorização dos Profissionais da Educação - Fundeb, de que trata o artigo 60 do Ato das Disposições Constitucionais Transitórias; altera a Lei $\mathrm{n}^{\circ}$ 10.195, de 14 de fevereiro de 2001; revoga dispositivos das Leis $n^{\circ}$ 9.424, de 24 de dezembro de 1996, 10.880, de 9 de junho de 2004, e 10.845, de 5 de março de 2004; e dá outras providências. Diário Oficial da União. Brasília: Casa Civil, 2007. Disponível em: <http://www.planalto.gov. br/ccivil_03/_ato2007-2010/2007/lei/111494.htm>. Acesso em: 12 nov. 2016

BRASIL. Lei no 11.738 , de 16 de julho de 2008. Regulamenta a alínea "e" do inciso III do capítulo do artigo 60 do Ato das Disposições Constitucionais Transitórias, para instituir o piso salarial profissional nacional para os profissionais do magistério público da educação básica. Diário Oficial da União. Brasília: Casa Civil, 2008.

BRASIL. Ministério da Educação. CONAE 2010 Conferência Nacional de Educação. Construindo o Sistema Nacional Articulado de Educação: O Plano Nacional de Educação, Diretrizes e Estratégias de Ação. Documento Final. Brasília: MEC, 2010a. Disponível em: <http://conae.mec.gov.br/images/stories/pdf/pdf/documetos/documento_final_sl.pdf>. Acesso em: 05 dez. 2016.

BRASIL. Ministério da Educação. Projeto de Lei no 8.035/2010. Aprova o Plano Nacional de Educação para o decênio 2011-2020 e dá outras providências. Brasília: MEC, 2010b. Disponível em: <http://www.camara.gov.br/ proposicoesWeb/ prop_mostrarintegra?codteor=831421\&filename=PL+8035/2010 >. Acesso em: 12 nov. 2016.

BRASIL. Lei no 13.005, de 25 de junho de 2014. Aprova o Plano Nacional de Educação - PNE e dá outras providências. Diário Oficial da União. Brasília: Casa Civil, 2014. Disponível em: <http://www.planalto.gov.br/ccivil_03/_ ato2011-2014/2014/lei/113005.htm>. Acesso em: 12 nov. 2016. 
BRASIL. Decreto 9.255, de 29 de dezembro de 2017, que Regulamenta a Lei no 13.152, de 29 de julho de 2015, que dispõe sobre o valor do salário-mínimo e a sua política de valorização de longo prazo. Disponível em: <http://www2. camara.leg.br/legin/fed/decret/2017/decreto-9255-29-dezembro-2017-786044-publicacaooriginal-154677-pe. html>. Acesso em: 17 jul. 2019.

CASTRO. Jorge Abrahão de. Financiamento e gasto público na educação básica no Brasil: 1995-2005. Educação e Sociedade, Campinas, v. 28, n. 100, p. 857-876, out. 2007. Disponível em: <http://www.scielo.br/pdf/es/v28n100/ a1128100.pdf>. Acesso em: 15 nov. 2016.

CONFEDERAÇÃO NACIONAL DOS TRABALHADORES EM EDUCAÇÃO. Saiba quais estados brasileiros não respeitam a Lei do Piso. Brasília: CNTE, 2019. Disponível em: <https://www.cnte.org.br/index.php/menu/ tabela-salarial>. Acesso em: 17 jul. 2019.

FACCI, Marilda Gonçalves Dias. Valorização ou esvaziamento do trabalho do professor?: um estudo crítico-comparativo da teoria do professor reflexivo, do construtivismo e da psicologia vigotskiana. Campinas, SP: Autores Associados, 2004.

FERNANDES, Marinalva Nunes. Tempo e salário: as contradições da lei do piso salarial profissional nacional do magistério. 2015. Tese (Doutorado em Educação) - Pontifícia Universidade Católica de Goiás, Goiânia, 2015.

HERMIDA, Jorge Fernando. O Plano Nacional de Educação (Lei 10.172), de 9 de janeiro de 2001. Educar, Curitiba, n. 27, p. 239-258, 2006. Disponível em: <http://www. scielo.br/pdf/er/n27/a15n27.pdf>. Acesso em: 15 nov. 2016. KOSIK, Karel. Dialética do concreto. Rio de Janeiro: Paz e Terra, 1976.

MARX, Karl. O capital: crítica da economia política. Livro I: o processo de produção do capital. São Paulo: Boitempo, 2013.

MONLEVADE, João Antônio Cabral de. Valorização salarial dos professores: o papel do Piso Salarial Profissional Nacional como instrumento de valorização dos professores da educação básica pública. 2000. Tese (Doutorado em Educação) - Faculdade de Educação, Universidade Estadual de Campinas, Campinas, 2000.

MOURA, Eliel da Silva. A construção do Plano Nacional de Educação 2014-2024: movimentos sociais e participação na tramitação no legislativo. 2015. Dissertação (Mestrado em Educação) - Faculdade de Educação, Universidade Federal Fluminense, Niterói, 2015.

RAMOS, Géssica Priscila. Entre a proposta e o pretexto da qualidade de ensino: uma leitura sobre os liames da valorização docente a partir do Fundef. 2008. Tese (Doutorado em Educação) - Centro de Educação e Ciências Humanas, Universidade Federal de São Carlos, São Carlos, 2008.

ROCHA, Maria da Consolação. Políticas de valorização do magistério: remuneração, plano de carreira, condições de trabalho - uma análise da experiência de Belo Horizonte. 2009. Tese (Doutorado em Educação) - Programa de Pós-Graduação em Educação, Faculdade de Educação, Universidade de São Paulo, São Paulo, 2009.

RODRIGUES, Robson da Silva. A "valorização dos profissionais da educação": reflexões a partir do Plano Nacional de Educação 2001-2010. 2013. Trabalho de Conclusão de Curso (Graduação em Licenciatura Plena em Pedagogia) - Centro de Educação e Ciências Humanas, Universidade Federal de São Carlos, São Carlos, 2013.

SILVA, Carmen Luiza da. Plano Nacional de Educação - PNE 2014/2024: evidências da conciliação política. 2014. Tese (Doutorado em Educação) - Universidade Tuitui do Paraná, Curitiba, 2014.

SOUZA, Maria Verônica de. A CONAE 2010 e os apontamentos para a política de valorização docente. 2012. Dissertação (Mestrado em Educação) - Universidade Federal da Grande Dourados, Dourados, 2012.

TEIXEIRA, Larissa. Piso Nacional do magistério vai a R\$ 2.455. Você acha bom? Nova Escola, São Paulo, 3 jan. 2018. Disponível em: < https://novaescola.org.br/conteudo/9425/piso-nacional-do-magisterio-sera-de-r245535-em-2018>. Acesso em: 17 jul. 2019. 

ardilosas apropriações da noção de valorização do trabalho docente

VIEIRA, Juçara Dutra. Piso salarial para os educadores brasileiros: quem toma partido? Campinas, SP: Autores Associados, 2013.

VILLELA, Heloisa de O. S. O mestre-escola e a professora. In: LOPES, Eliane Marta Teixeira; FARIA F., Luciano Mendes; VEIGA, Cynthia Greive. 500 anos de educação no Brasil. 3. ed. Belo Horizonte: Autêntica, 2003. p. 95134.

Recebido em: 18/08/2017

Aceito em: 17/04/2019 